Research Report

\title{
Sex determination using gonial angle during growth spurt period: a direct examination
}

\author{
Monica Hariemmy, Rizky Merdietio Boedi, Haryono Utomo, Mieke Sylvia Margaretha \\ Department of Forensic Odontology, Faculty of Dental Medicine \\ Universitas Airlangga \\ Surabaya - Indonesia
}

\begin{abstract}
Background: In forensic medicine and medicolegal, sex determination is an important step of an identification process. Parts of human skeleton that can be used for identification are cranium, pelvis, and mandible. There are several anthropometry tools in sex determination methods i.e shape of mandible, mental, gonial angle. Gonial angle in adults is an excellent tool for sex determination. However, bone density and masticatory force may change the value of gonial angle. Purpose: The objective of this study was to examine sex determination method using gonial angle in children during grow spurt period and external factors. Methods: There were 104 randomly selected subjects (51 boys and 53 girls) aged 7-12 years old. The subjects were grouped into prolonged sun exposure-hard diet (group A) and low sun exposure-soft diet (group B). The measurements were made using goniometer. Results: The mean of gonial angle of female children was greater than the male children. There was no significant difference between group A and B. Conclusion: Gonial angle can be used for sex determination in grow spurt period, and external factors did not affect sexual dimorphism.
\end{abstract}

Keywords: sexual dimorphism, gonial angle, goniometer

Correspondence: Mieke Sylvia Margaretha, Department of Forensic Odontology, Faculty of Dental Medicine Universitas Airlangga, Jl. Mayjend. Prof. Dr. Moestopo No. 47 Surabaya - Indonesia. Phone: +62315030255 Email: mieke-s-m-a-r@fkg.unair.ac.id

\section{INTRODUCTION}

Geographically, Indonesia is a country prone to natural disasters. In case of natural disaster, some deceased are found in a damaged or unrecognizable state. Therefore, sex determination is a crucial identification in forensic and medicolegal anthropology to determine the identity of the deceased. ${ }^{1,2}$

Mandible is one of the valid parts of the skull for sex determination. Mandible is the strongest facial bone that curves horizontally, convex in the two ramus of mandibles, and ascends to the posterior end of the mandibular corpus., ${ }^{3,4}$ Parts of the mandible that can be used in sex determination are the symphysis, the corpus, ramus, and the gonial angle (GA). ${ }^{5-9}$

GA is formed from two lines, the inferior border of the mandibular corpus and the posterior border of the mandible ramus. ${ }^{10}$ Physiologically, GA is blunt at birtha $\left(175^{\circ}\right)$ and shrinks in the second year $\left(140^{\circ}\right)$. In adults, the angle is between $110^{\circ}-120^{\circ}$ whereas in the old age group, gonial angles again increased to $140^{\circ}$ due to tooth loss. ${ }^{11,12} \mathrm{GA}$ growth can be directly measured using odonto pantomograph (OPG) and goniometer for sex determination. ${ }^{10,13}$ However, in the event that mandibular skeleton is left, OPG cannot be used. Thus, a direct measurement method with a goniometer is needed.

Growth spurt and external factors such as food texture and vitamin D from sun exposure can affect GA measurement. ${ }^{14,15-17}$ The mandible development during growth spurt does not affect the GA. ${ }^{2}$ In addition, after bone growth and development stops due to hormonal effects, the difference will appear clearly. ${ }^{18}$ Therefore, internal and external factors must be considered. This study aimed to examine gonial angle method as sex determination tool of children during growth spurt and external factors.

\section{MATERIALS AND METHODS}

This was an observational analytic study with a cross sectional design. Ethical clearance was obtained from the Health Research Ethical Clearance Commission, Faculty of Dental Medicine, Universitas Airlangga 051/HRECC. FODM/II/2019. The participants of the study were children 7-12 years old totaling 104 subjects (51 male children and 53 female children). The participants were Kalijudan I Public Elementary School of Kalijudan area, Mulyorejo District and Muhammadiyah 4 Private Elementary School 
of Kertajaya area, Gubeng District, Surabaya. The subjects were divided into 2 groups. Subjects with prolonged sun exposure and hard diets (Group A), and subjects with low sun exposure and soft diets (Group B). ${ }^{15,16,19}$

Subject criteria were no genetic and physical defects, no cross-bite, and median line shifts. Parents/guardians have signed an agreement that the data obtained would be used for research purposes and given a questionnaire to confirm the information provided by the subjects. Subjects were interviewed regarding dietary habits and outdoor activities.

The tools and materials were goniometer, gonial angle (GA), cross stickers, stationery. Right and left GA were measured by placing cross stickers onto the inferior parts of the mandibular corpus and posterior ramus of the mandible (Figure 1).

The measurement was made by one examiner. To examine the reliability between the observers, $10 \%$ subjects were randomly selected and re-evaluated after 1 month. The data were collected using Excel (2013 version of Microsoft, Redmond, USA) and statistically analyzed using SPSS (version 21.0 of IBM Corporation, Armonk, New York).

Data obtained from the examiners were tested using Kolmogorov-Smirnov to determine whether the data were normally distributed, then tested with the KruskalWallis Test. The difference between right and left GA was examined by the Mann-Whitney Test. The differences of GA for each sex were tested using independent t-test. The MannWhitney Test was used to find out if there were significant differences between the GA groups. The Independent t-test

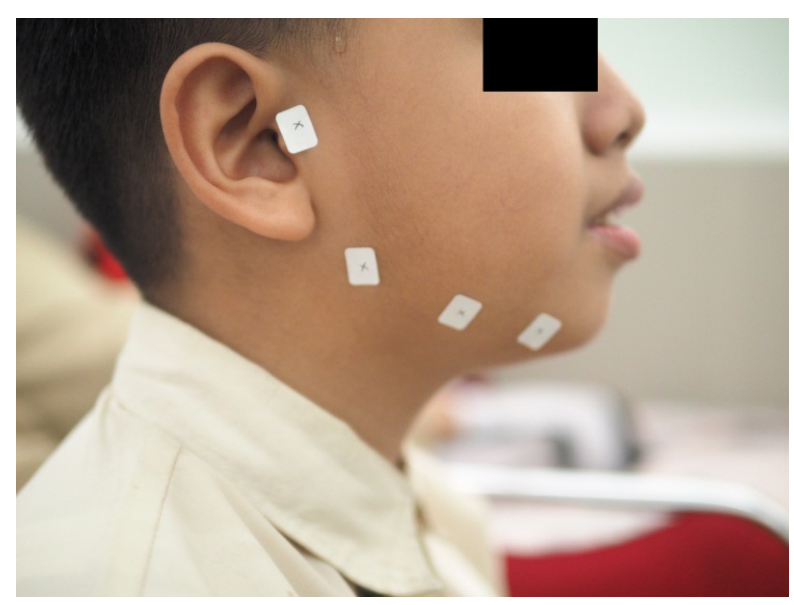

Figure 1. A cross sticker is placed inferior to the mandibular corpus and posterior to the mandibular ramus and the Mann-Whitney test were used to determine the differences between the sexes in group $\mathrm{A}$ and $\mathrm{B}$.

\section{RESULTS}

The mean of GA measurement confirmed that there was no difference in term of data $(p>0.05)$. The mean of right and left GA showed no significant difference $(\mathrm{p}>0.05)$, obtained from each sample (Table 1). Furthermore, there were significant differences between male and female where the mean of GA of female was greater than the male ( $p=$ 0.002) as listed in Table 2. The mean of GA in Group B showed no significant difference between male and female $(p=0.001)$ (Table 3$)$. In contrast, there was no significant difference in the mean of GA between group A and B ( $p$ $=0.597)$.

\section{DISCUSSION}

Differences of mandible are pictured in shape and size. In addition, the development of the mandible differs between male and female.20 We found no significant differences between the mean of left and right GA of all male and female samples (130.94 o and $130.93 \mathrm{o}, \mathrm{p}=.858$ ). Research Shahabi et al., (2009)21 involving 70 orthodontic patients (48 females and 22 males) aged 15-30 years old resulted in a similar result that there was no difference between the mean of left and right GA using orthopantomogram (OPG) and

Table 1. Analysis of right and left gonial angles

\begin{tabular}{|l|c|c|c|c|}
\hline Variables & $\begin{array}{c}\text { Number of } \\
\text { Samples }\end{array}$ & Mean & $\begin{array}{c}\text { Standard } \\
\text { Deviation }\end{array}$ & $\begin{array}{c}\mathrm{p}- \\
\text { Value }\end{array}$ \\
\cline { 1 - 3 } Right GA & \multirow{2}{*}{104} & $130.93^{\circ}$ & 5.22274 & \multirow{2}{*}{0.858} \\
\cline { 3 - 5 } Left GA & $130.94^{\circ}$ & 5.93426 & \\
\hline \multicolumn{2}{|l}{ Note: GA: gonial angle }
\end{tabular}

Table 2. Analysis of gonial angles based on sex

\begin{tabular}{|l|c|c|c|c|}
\hline Variables & $\begin{array}{c}\text { Number of } \\
\text { Samples }\end{array}$ & Mean & $\begin{array}{c}\text { Standard } \\
\text { Deviation }\end{array}$ & $\begin{array}{c}\mathrm{p}- \\
\text { Value }\end{array}$ \\
\cline { 1 - 4 } GA M & 51 & $129.3^{\circ}$ & 5.5820 & \multirow{2}{*}{0.002} \\
\cline { 1 - 4 } GA F & 53 & $132.4^{\circ}$ & 4.5879 & \\
\hline
\end{tabular}

Table 3. Analysis of gonial angles in group A and B

\begin{tabular}{|c|c|c|c|c|c|c|}
\hline \multirow{2}{*}{ Variables } & \multirow{2}{*}{$\begin{array}{l}\text { Number of } \\
\text { Samples }\end{array}$} & \multicolumn{2}{|c|}{ M } & \multicolumn{2}{|c|}{$\mathrm{F}$} & \multirow[b]{2}{*}{ p-Value } \\
\hline & & Mean & $\begin{array}{c}\text { Standard } \\
\text { Deviation }\end{array}$ & Mean & $\begin{array}{c}\text { Standard } \\
\text { Deviation }\end{array}$ & \\
\hline GA of Group A & 51 & $128.7^{\circ}$ & 7.2207 & $132.3^{\circ}$ & 5.6579 & 0.061 \\
\hline GA of Group B & 53 & $129.9^{\circ}$ & 2.4412 & $132.6^{\circ}$ & 5.6579 & 0.001 \\
\hline
\end{tabular}


lateral cephalogram. Another research showed that the mean of GA in lateral cephalograms is 2.2-3.6 degrees greater than panoramic radiographs. 22 This insignificant difference can affect the accuracy of forward logistic regression.

The mean of GA is a useful and proven variable in sex determination because there are significant differences between male and female (129.3o and $132.4 \mathrm{o}, \mathrm{p}=0.002)$. Several researches showed that GA is reliable for sex determination in various age groups.2,23-26 In contrast, other research found that there was no significance between the mean of male and female GA.27

Research conducted by Hichijo et al., (2015)13 and Kono et al., (2017)15 showed that the mean of GA of soft diet group was higher than the hard diet group. Soft diet can have a negative impact on mandible growth, while hard diet can repair bone damage caused by soft diet during growth. 28 In addition, sun exposure is associated with bone health.29 The effect of sun exposure can have a positive impact on bone structure and hormones that control bone mass.30 Kanemura et al., (2016)16 researched the effect of sun exposure on bone thickness in 5 children aged 6-8 years old for 12 months. The results showed that bone mineral density (BMD) significantly increased in all children who bask in sun exposure for an average of 28.8 minutes/day compared to children who did not bask in the sun, and all children did not experience bone fracture after 2 years of observation. In comparison to this study, we found no significant difference of mean of GA between group A and $B(p=0.597)$. Possible causes are inclusion and exclusion criteria. For future research, it is recommended add other factors to the questionnaire such as race, oral habits, chewing habits, menarche, body mass index (BMI).31-36

In this study, the goniometer was chosen as the GA measurement method. Goniometer can be used directly on the patient's face. The advantages of a goniometer are simple, unlimited use, inexpensive, and safe.37-38 In addition, the disadvantages of goniometer are, first, measurements are carried out one by one per variable. 39 Second, the researchers have difficulty determining the inferior border and posterior ramus of the mandible. Gungor et al., (2007)40 found that OPG can accurately measure GA and can be used directly on the skull. However, in the event that only skull mandible is left, OPG cannot be used. Therefore, a direct measurement method is needed because in some OPG cases, postmortem (PM) is not possible.41 This study showed that GA can be used as sex determination tool during growth spurt as the GAs of male and children were different. Mandibular growth in children aged 7-12 years old was not influenced by external factors

\section{REFERENSI}

1. Bencana BN. Peraturan Kepala BNPB Nomor 02 Tahun 2012 tentang Pedoman Umum Pengkajian Risiko Bencana. Jakarta (ID): BNPB. 2012.

2. Jambunath U, Govindraju P, Balaji P, Poornima C, Latha S. Former. Sex determination by using mandibular ramus and gonial angle - a preliminary comparative study. Int J Contem
Med Res. 2016 Nov;3:3278-80.

3. Abu-Taleb NS, El Beshlawy DM. Mandibular ramus and gonial angle measurements as predictors of sex and age in an Egyptian population sample: A digital panoramic study. Journal of Forensic Research. 2015 Sep 1;6(5):1.

4. Nagaraj S, Gayatri N, Sherke A. Study of Mandibular Ramus by Metric Parameters. Internasional Journal of Anatomy and Research. 2017 Vol 5(1): 3358-61.

5. Loth SR, Henneberg M. Sexually dimorphic mandibular morphology in the first few years of life. American Journal of Physical Anthropology: The Official Publication of the American Association of Physical Anthropologists. 2001 Jun;115(2):179-86. https://doi.org/10.1002/ajpa.1067

6. Björk A. Variations in the growth pattern of the human mandible: longitudinal radiographic study by the implant method. Journal of dental Research. 1963 Jan;42(1):400-11.

7. Lewis $\mathrm{AB}$, Roche AF, Wagner B. Growth of the mandible during pubescence. The Angle Orthodontist. 1982 Oct;52(4):325-42. https://doi.org/10.1043/00033219(1982)0 52<0325:GOTMDP $>2.0 . \mathrm{CO} ; 2$

8. Saini V, Srivastava R, Rai RK, Shamal SN, Singh TB, Tripathi SK. Mandibular ramus: an indicator for sex in fragmentary mandible. Journal of forensic sciences. 2011 Jan;56:S13-6. https://doi.org/10.1111/j.1556-4029.2010.01599.x

9. Kharoshah MA, Almadani O, Ghaleb SS, Zaki MK, Fattah YA. Sexual dimorphism of the mandible in a modern Egyptian population. Journal of Forensic and Legal Medicine. 2010 May 1;17(4):213-5. https://doi.org/10.1016/j. jflm.2010.02.005

10. Saikiran CH, Ramaswamy P, Santosh N, Sudhakar S, Smitha B. Can Gonial Measurements Predict Gender. A Prospective Analysis Using Digital Panoramic Radiographs. Forensic Res Criminol Int J. 2016;3(2):00089.

11. Dur-e-Shahwar Rehman SS, Nigar S. Association between changes in the angle of mandible and reduced bone mineral density. Journal of the College of Physicians and Surgeons Pakistan. 2015;25(2):87-90.

12. Jensen E, Palling M. The gonial angle: A survey. American Journal of Orthodontics. 1954 Feb 1;40(2):120-33.

13. Upadhyay RB, Upadhyay J, Agrawal P, Rao NN. Analysis of gonial angle in relation to age, gender, and dentition status by radiological and anthropometric methods. Journal of forensic dental sciences. 2012 Jan;4(1):29.

14. Rao A. Principles and practice of pedodontics. JP Medical Ltd; 2012 Jul 20.

15. Hichijo N, Tanaka E, Kawai N, van Ruijven LJ, Langenbach GE. Effects of decreased occlusal loading during growth on the mandibular bone characteristics. PloS one. 2015 Jun 10;10(6):e0129290.

16. Kanemura H, Hatakeyama K, Sano F, Yagasaki H, Sugita K, Aihara M. Effect of sunlight exposure on bone mineral density in children with severe disability. Neuropediatrics. 2016 Aug;47(04):233-7.

17. Kono K, Tanikawa C, Yanagita T, Kamioka H, Yamashiro T. A novel method to detect 3D mandibular changes related to soft-diet feeding. Frontiers in physiology. 2017 Aug 14;8:567.

18. Gurvich C, Hoy K, Thomas N, Kulkarni J. Sex differences and the influence of sex hormones on cognition through adulthood and the aging process. Brain sciences. 2018 Sep;8(9):163.

19. Gilchrest BA. Sun exposure and vitamin D sufficiency. The American journal of clinical nutrition. 2008 Aug 
$1 ; 88(2): 570 \mathrm{~S}-7 \mathrm{~S}$.

20. Sandeepa NC, Ganem AA, Alqhtani WA. Mandibular Indices for Gender Prediction: A Retrospective Radiographic Study in Saudi Population. of. 2017;7:2.

21. Shahabi M, Ramazanzadeh BA, Mokhber N. Comparison between the external gonial angle in panoramic radiographs and lateral cephalograms of adult patients with Class I malocclusion. Journal of oral science. 2009;51(3):425-9.

22. Fischer-Brandies H, Fischer-Brandies E, Dielert E. The mandibular angle in the orthopantomogram. Der Radiologe. 1984 Dec;24(12):547-9.

23. Leversha J, McKeough G, Myrteza A, SkjellrupWakefiled H, Welsh J, Sholapurkar A. Age and gender correlation of gonial angle, ramus height and bigonial width in dentate subjects in a dental school in Far North Queensland. Journal of clinical and experimental dentistry. 2016 Feb;8(1):e49.

24. Joo JK, Lim YJ, Kwon HB, Ahn SJ. Panoramic radiographic evaluation of the mandibular morphological changes in elderly dentate and edentulous subjects. Acta Odontologica Scandinavica. 2013 Mar 1;71(2):357-62.

25. Bhardwaj D, Kumar JS, Mohan V. Radiographic evaluation of mandible to predict the gender and age. Journal of clinical and diagnostic research: JCDR. 2014 Oct;8(10):ZC66.

26. Datta A, Siddappa SC, Gowda VK, Channabasappa SR, Shivalingappa SB, Dey D. A study of sex determination from human mandible using various morphometrical parameters. Indian Journal of Forensic and Community Medicine. 2015 Jul;2(3):158-66.

27. Saikiran CH, Ramaswamy P, Santosh N, Sudhakar S, Smitha B. Can Gonial Measurements Predict Gender. A Prospective Analysis Using Digital Panoramic Radiographs. Forensic Res Criminol Int J. 2016;3(2):00089.

28. Fujita Y, Maki K. Association of feeding behavior with jaw bone metabolism and tongue pressure. Japanese Dental Science Review. 2018 Sep 3.

29. Anand N, Chandrasekaran SC, Rajput NS. Vitamin $\mathrm{D}$ and periodontal health: Current concepts. Journal of Indian Society of Periodontology. 2013 May;17(3):302.

30. Abulmeaty MM. Sunlight exposure vs. vitamin D supplementation on bone homeostasis of vitamin D deficient rats. Clinical Nutrition Experimental. 2017 Feb 1;11:1-9.

31. Sitanggang M, Boel T, Pintauli S. Gonial Angle Changes Based on Age Group on Mongoloid Race in Medan City in Terms of Lateral Cephalometric Radiograph. International Dental Conference of Sumatera Utara 2017 (IDCSU 2017) 2018 Feb 7. Atlantis Press.

32. Grippaudo C, Paolantonio EG, Antonini G, Saulle R, La Torre G, Deli R. Association between oral habits, mouth breathing and malocclusion. Acta Otorhinolaryngologica Italica. 2016 Oct;36(5):386. Sadeghianrizi A, Forsberg CM, Marcus C, Dahllöf
G. Craniofacial development in obese adolescents. The European Journal of Orthodontics. 2005 Jul $11 ; 27(6): 550-5$.

33. Urzal V, Braga AC, Ferreira AP. Oral habits as risk factors for anterior open bite in the deciduous and mixed dentition-cross-sectional study. European journal of paediatric dentistry: official journal of European Academy of Paediatric Dentistry. 2013 Dec;14(4):299-302.

34. Reinhardt R, Treml T, Reinhardt W, Wehrbein H, Gupta R. Gonial angle, angle class and functional harmony. Journal of Indian Orthodontic Society. 2007 Oct 1;41(4):119.

35. Tofani MI. Mandibular growth at puberty. American Journal of Orthodontics. 1972 Aug 1;62(2):176-95.

36. Sadeghianrizi A, Forsberg CM, Marcus C, Dahllöf G. Craniofacial development in obese adolescents. The European Journal of Orthodontics. $2005 \mathrm{Jul}$ $11 ; 27(6): 550-5$.

37. Neger M. The facial goniometer: an instrument for the direct measurement of the Frankfort-mandibular plane angle and the gonion angle. The Angle Orthodontist. 1951 Oct;21(4):198-204.

38. Rupa K, Chatra L, Shenai P, Veena K, Rao P, Prabhu R, Kushraj T, Shetty P, Hameed S. Gonial angle and ramus height as sex determinants: A radiographic pilot study. Journal of Cranio-Maxillary Diseases. 2015 Jul $1 ; 4(2): 111-$

39. Nariño Lescay R, Alonso Becerra A, Hernández González A. Anthropometry. Comparative analysis of technologies for the capture of anthropometric dimensions. Revista eia. $2016 \operatorname{Dec}(26): 47-59$.

40. Gungor K, Sagir M, Ozer I. Evaluation of the gonial angle in the Anatolian populations: from past to present. Collegium antropologicum. 2007 Apr 10;31(2):375-8.

41. Du Chesne A, Benthaus S, Teige K, Brinkmann B. Post-mortem orthopantomography-an aid in screening for identification purposes. International journal of legal medicine. 2000 Feb 1;113(2):63-9. https://doi. org/10.1007/PL00007710 